and the lower eyelid was everted and very much swollen, with chemosis of eyeball. The eveball was slightly displaced down and outward. I saw the patient on the 2nd of October (he liaving been referred to me by Dr. Moffat) ; œdema of lids had disappeared, eye slightly deranged, with some redness of conjunctiva, pupil moderately dilated which did not respond to direct rays of light, but acted consensually with the fellow eyc. Ophthalmoscopic examination showed some pallor of optic nerve of left-but fundus otherwise normal. Vision nil. Right normal in every respect.

Dec. 5th, 1891. Patient presented himself, after an absence of three weeks, when I found the divergence not so marked as on the previous visit, pupil moderately dilated, but there was enough vision regained for the patient to count my fingers at eight feet. Ophthalmoscopic exainination showed more marked pallor of optic; nerve fundus otherwise normal. Dec. 27, 1891, condition remains the same. Jan. 17, 1892. Still able to count my fingers when held about eight feet from his left eye, but the ophthalmoscope showed the atrophy of optic nerve more marked.

Julius S., aged 30. Patient fell from the track of the Metropolitan Elovated Railroad, on the afternoon of the 9 th of October, 1891. He was conveyed to St. Vincent's Hospital, when on examination by the House Surgeon, Dr. Shea, there was found blood coming from right ear and nose, left side of head and face contused, with wound of left orbital ridge and patient. in a semi-unconscious condition. On the third day after the fall of patient from the track I saw him; he lay in a stupor and when aroused he complained of great pain all over his head. In falling he tried to save his face, so that he struck on the left side of his head. He complained about his left eye, saying that since the accident it had become blind. There was no swelling of the eyelids, the eyeball was slightly diverged, but he could move the cornea well in toward the inner canthus. no protrusion of the globe, pupil slightly enlarged, but it did not respond to direct rays of light, but acted feebly consensually with that of right eye. Ophthalmoscopic examination showed the fundus of left eye normal. No light perception. Right eye normal in all respects, except the pupil was rather contracted. Saw patient at regular interrals and at the end of two weeks there was found by the ophthalmoscopic examination, decided pallor of of optic nerve (left eye). Patient continues under my observation, and now, Feh. 1892, optic nerve atrophy pronounced of left eye. No light perception.

The medico-legal aspect of this lesion is quite apparent and is of considerable importance.

I am fully satisfied that the optic foramina are frequently involved in fractures of the skull, but as most of the severe cases die, this lesion is neither looked for nor recognized. If the autopsy is not carefully made, hy removing all the dura mater within the cranial cavity, and this means bard work, a fissure involving the optic foramen easily escapes attention. It has been my lot to see the four cases which comprise this paper within the past two years, which is remarkable from the fact that there are not more than 80 recorded cases in medical literature.

A twenty-five per cent. ointment of resorcin in vaseline is recommended in the treatment of rodent ulcer.

\section{A CASE OF MALIGNANT PLSTULE.}

Reported to the Bunscombe Co. Medical society, Feb. 1, 189: BY KARI, VON RUCK, B.S., M.D., OF ASHEVILLE, Y. C:

That comparatively rare affections may come to our notice when least expected we all have learned from experience, and it is certainly one of the last of improbable cases that I should have imagined to present itself to me, the more so, as I am not engaged in general practice.

Nevertheless, on Dec. 8th, a patient who has been under my care more or less for the last three years, on account of his pulmonary affection, called upon me with the following statement: on noon of the day before, he noticed a spot on the inner aspect of the first phalanx of the fore-finger of his left hand, looking like a flea bite, which attracted his attention on account of severe itching; by evening a vesicle had formed surrounded by a red areola, and a burning, stinging sensation was also present; the finger and surrounding parts had become slightly swollen.

The patient presented himself the following morning, calling my attention to his finger. The vesicle was now about three-eighths of an inch in diameter, the elevated epidermis was of a dark discoloration and gangrenous, the base was indurated, and spontaneous rupture of the vesicle had occurred, a serous, pink-colored fluid discharging, so that a drop could be collected every five or ten minutes.

The first phalanx of the finger, the phalangometa-carpal joint, and the hand were distinctly swollen, the skin presenting a red blush, the vesicle had a stinging, burning sensation, the whole hand to the wrist pained him, the local temperature of the hand was distinctly increased to the touch; there were, however, nogeneral symptoms, unless a temperature of $99.5^{\circ} \mathrm{F}$., could be so interpreted.

The patient was in my office from 9:30 to 1 o'clock, and the swelling and size of the vesicle had undoubtedly increased; a very minute vesicle, independent of the larger one, which was not present in the morning, was now observed at the edge of the indurated base. Eight years ago, in the Hygienic Institute in Berlin, I saw experimental inoculations of guinea pigs and rabbits with anthrax bacilli, and within the last few months, I had reviewed the subject of anthrax in connection with some bacteriological studies-but for these circumstances, I should perhaps have had no suspicion of the serious character of the nature of this case.

From what I remembered, the probability of malignant pustule at once occurred to me, and my inquiries only served to strengthen the suspicions, while the local appearance and the history given by the patient conformed entirely to descriptions of my available, and promptly consulted medical literature. I suggested the propriety of consultation, which was readily concurred in by the patient, in the meanwhile subjecting the discharging serum to microscopical examination, with, however, negative results. While my consultant could not be more positive than I was myself, it was determined to endeavor to make a culture from the discharging serum, and to promptly and thoroughly destroy the vesicle and its base with fuming nitric acid. This was done accordingly, and the patient allowed to return home with instructions to return or send for us, should general symptoms, which were explained to him, occur. 
Before the application of the nitric acid, two large apeutic application of drugs in the cure of dipsomadrops of the discharging serum were collected upon nia and kindred diseases.

sterilized slides and put into a moist brood-oven as hanging drops, with a temperature of $100^{\circ} \mathrm{F}$.

In three hours one specimen was removed and examined, and the characteristic growth of the anthrax bacillus left no further doubt of the diagnosis. The bacilli were present in various stages and phases of development, some grown out to long rods, others shorter, and in some upon the periphery, where in the brood-oven the drop had slightly dried, the rods were quite short; subsequent experiments with the specimens gave similar results.

The patient returned the following morning; the swelling had greatly subsided, a dry eschar having formed where the acid had been applied. Nothing further occurred, the swelling had all disappeared by the second day and healing resulted promptly.

There is, gentlemen, no reasonable doubt, that this case was one of anthrax, but much obscurity and doubt exists, as to how and where the infection occurred. I am not aware of the disease prevailing in this locality among cattle.

The patient had recently been engaged in handling and buying cattle and the same day and the day before the pustule appeared on his finger, he had also cleaned out with his hands, the mangers in his cattle barn. He also stated that one of his horses had an ugly sore on his head where the bridle comes in contact, and he had handled the sore and the bridle.

None of his cattle died before ${ }^{1}$ or have become sick since, and, altogether, the origin of the pustule remains more or less a mystery.

The lesson we can all learn from this case is, as I stated in the beginning, that although living in a small community, we may at any time, be confronted with unexpected and infrequent affections, possibly of the gravest character, which, if upon them we are indifferently or not at all informed, may possibly terminate fatally, before we can be set right in our diagnosic

It teaches us the necessity of frequent reviews of subjects, which have apparently had only general interest in our previous study, and also the great importance of familiarity with microscopical and bacteriological investigations.

\section{ALCOHOLISII A IISEASE.}

BY A. ENFIELD, M.D.

OF BEDFOHD SPRINGS SANITAKITM, BEDFORD. PA. MENBER OF TIE BED FORD COCNTY MEDICAL SOKIETY, THE STATE MEDICAL NOCIETY, AND

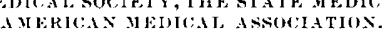

The day of medical theories, which do not have established facts to justify them, belongs to the past. It has taken ages of observation and investigation, by the greatest intellects of the profession, to elevate the science of medicine to the high position it now occupies. We live in an age of light and knowledge, an age in which old isms, theories and fallacies, are fast disappearing before the sweeping progress of this century.

The past decade has given us the beginning of a new epoch in the science of life. Nedical science is now called upon to defend our bodies from the parasites which prey upon us from without, and physiological and chemical research has taught us the ther-

1 It has since come to my knowledge, that a cow died suddenly in hi herd a month or two before the ocenrrence of this case.

The power of self-regeneration is one of the great distinctive properties belonging to all organized living bodies; but the moment we commence to live we begin to die. Molecular changes may be increased or retarded by various foods and drugs, taken into the system at stated periods. W'e apply the term hunger to that peculiar want felt by the human system for food, a sensation (when not too prolonged) by no means disagreeable, and one which is often excited by the sight or smell of a savory dish.

It is true that the taking of food is influenced in some degree by exercise and habit, as well as by the sense of hunger, and if our systems are not supplied at regular intervals by this nourishment, the sensation of hunger becomes so great that we suffer great pain and distress.

All the elements necessary to mutrition (except oxygen and light) can be taken into the system by the mouth, and if it.were not that there comes a time in the history of every organized body, when the tissues fail to appropriate sufficient new material to repair the waste, we would continue to live forever. Death is therefore a physiological necessity. Therefore, there is no such a thing as true euthanasia. But it is the duty of the physician to secure for man such good health as shall bear him, in activity and happiness, onward in lis course to the goal. Good health and happiness can be secured by living in oledience to the laws of health. When the medical profession succeed in teaching the world how to live in a proximate physiological, normal condition, then they have reached the consummation of their calling.

Fifty years ago there was not a medical college, in Europe or America, that had a special chair of neurology, whereas to-day there is not a school that has not at least one such chair, and some schools have two, or even three professors who are giving their whole time and attention to discoveries and advancements in this important branch of medical science.

It is therefore gratifying to the American student of scientific medicine to note the amazing progress that has recently been made in the discovery and cure of nervous diseases, especially hy American neurologists.

It was our own beloved Rush who a century ago stood as the great pioneer (in advance of all the world), to describe and clearly demonstrate the future of this branch of medical science. It was men like Rusl, Pinel, Brown-Séquard and others, who taught us that insanity is a disease, and not the devil in man, as was generally supposed prior to their time So that to day, while medicine is advancing all along the line, in no other department has there been such advancement as in the discovery and treatment of nervous diseases. Advancement has been so rapid in this special department of medicine, that some writers claim that all diseased manifestations are but the result of nervous shock.

Vesalins took his own life in his hands when he was brave enough to sharpen his scalpel for the first dissection on the human body. Galen followed, and taught us that the arteries contained blood and not air, and Harvey showed us how that blood circulated. Jenner, Pasteur and Koch have been bold enough to transfuse the very elements of chemistry into our blood, in order to kill the myriads of germs that infest our organisms, and produce disease and death. 